Article

\title{
A Multi-Stage Approach to a Hybrid Lead Acid Battery and Supercapacitor System for Transport Vehicles
}

\author{
Mpho J. Lencwe* * , Shyama P. Chowdhury and Thomas O. Olwal \\ Department of Electrical Engineering, Tshwane University of Technology, Pretoria 0001, South Africa; \\ spchowdhury2010@gmail.com (S.P.C.); OlwalTO@tut.ac.za (T.O.O.) \\ * Correspondence: mpholencwe@gmail.com; Tel.: +27-78-097-5204
}

Received: 6 October 2018; Accepted: 20 October 2018; Published: 24 October 2018

\begin{abstract}
Lead Acid Batteries (LABs) are used for starting, lighting, and igniting, as well as in air conditioning systems and to supply power to electric engines in transport vehicles (TVs). However, the application of LABs for TVs has faced a number of market challenges, mounted by the upcoming high energy density and long lifespan batteries, such as lithium ion. LABs, on the other hand, are inexpensive. The key research question is, how can the lifespan of LABs used in automotive industries be increased, while still ensuring a low cost solution? Thus, integrating LABs with the supercapacitor (known as an electric double layer capacitor-EDLC) is likely to outperform the competing alternative batteries for TVs. This paper proposes a multiple stage approach to hybrid lead acid batteries and a supercapacitor system for TVs that is capable of maintaining the battery state-of-charge (SOC) at statistically high limits, ranging between $90 \%$ and $95 \%$. This SOC target will likely ensure that the lifespan of the hybrid battery system can be elongated (extended) more than its competitors. In this study, the multiple stage approach of concatenated converters has been designed in order to satisfy all energy storage requirements for different characteristics of LABs and the supercapacitor. The designed hybrid system has been simulated using Matrix Laboratory (MATLAB/Simulink (version R2016a, MathWorks, Natick, MA, USA)). The simulated results show that high transient currents from the direct current (DC) bus of LABs, caused by the regenerative braking or deceleration of the TVs, reduce the battery lifespan and induce mechanical stress. The supercapacitor reduces the stress on the LAB by absorbing high transient currents. This, in turn, keeps the LABs' SOC between $90 \%$ and $96 \%$ and the voltage at $12 \mathrm{~V}$. As indicated by the simulated results, the hybrid battery SOC is maintained at $90-96 \%$ and the terminal voltage is approximately $12 \mathrm{~V}$.
\end{abstract}

Keywords: lead acid battery; supercapacitor; DC /DC converter; state-of-charge

\section{Introduction}

Many applications have seen the widespread use of lead acid batteries (LABs) and supercapacitors in recent years. Supercapacitors, known as electric double layer capacitors (EDLC), are the workhorse in many applications in the automotive sector, due to their ability to last longer and absorb/provide high currents, and their high efficiency. As compared with LABs, supercapacitors have common characteristics of being inexpensive and robustness, amongst other factors. Batteries alone are unable to provide the required energy for future vehicles (i.e., hybrid vehicles, electric vehicles, and plugged-in hybrid electric vehicles) [1-4].

Hybrid electric vehicles (HEVs) have been heavily introduced to the market because of their low carbon emission and flexibility. These vehicles demand high energy storage devices for their operation. Therefore, batteries alone cannot satisfy HEVs' demands. LABs are used for starting, lighting, 
and igniting, as well as in air conditioning systems. Above and beyond these functions, LABs are responsible for supplying power to electric engines. Presently, the core technical challenges encountered by automotive industries involve battery lifespan. The function of the supercapacitor is to permit the battery to handle the normal energy requirements, whereas the supercapacitor handles the high power requirements. Furthermore, the supercapacitor leads to reduced $\mathrm{CO}_{2}$ emission, better fuel consumption, and advanced electrical drive capabilities. With supercapacitors, recapturing and re-use of power in regenerative braking is possible [5]. Energy management control is the most important part in hybrid energy storage systems (HESS) for transport vehicles. In the work of [6], a combination of parallel-active system comprising of lithium ion and a supercapacitor has been studied, it is claimed that integrating both energy storage technologies provides an energy storage system with high energy availability combined with high power density. However, the parallel-active topology is not suitable for use in transport vehicles (TVs), because the supercapacitor tends to charge from the battery when the system is not operational.

Although the authors of [7] developed a hybrid topology for LABs and supercapacitors with a single direct current-to-direct current (DC/DC) converter. The system lacks the ability to keep the battery voltage and state-of-charge (SOC) within high statistical limits to enhance the battery lifetime. Moreover, battery current is claimed to be lowered, although no quantity is shown to prove the claims. Two DC/DC converter topologies for LAB/supercapacitor are proposed by the authors of [8]. These include the two base controllers that are embedded in the management strategy of both the DC/DC converters, which includes the lyapunov function that regulates the bus voltage and the sliding-mode function that keeps the battery and supercapacitor current at reference value. The problem with this topology is that the supercapacitor tends to charge from the battery during normal operating mode.

In the work of [9], it is illustrated that two topologies exist for interfacing energy storage systems, namely single- and double-stage topology. Single-stage topology only controls the charge/discharge of the storage systems, whereas the double-stage topology consists of two converters, namely DC/DC to control the charge/discharge of the storage systems and DC/AC to interface with the AC load or grid. Furthermore, the DC/DC converter used in automotive applications needs to have certain characteristics, including high step-up ratio; high power density due to space limitation; and high efficiency, greater than $90 \%$ [10].

Nguyen et al. [11] emphasized the importance and need for optimal energy management strategies, in order to enhance the overall energy efficiency in EVs. The main consideration in this study is the electrical super charger (eSC) in the engine compartment of the turbo-air charged system. In this study, the supercapacitor played two main functions, that is, providing high currents at high transition phases to protect the battery from fatal damages and over-discharge, as well as reducing energy from regenerative braking and reducing the battery size. In the work of [12], a battery/supercapacitor hybrid is developed. In this design, the supercapacitor's function is to provide extra energy required to the EV load when the battery fails to deliver. The design is the result of the batteries losing their performance over a prolonged period at peak demand operation. It is further emphasized that this is of paramount importance to employ decision-based control strategies of deciding when and how the electrochemical cells should be charged/discharged. However, the study focused on understanding the phenomenon of designing the battery/supercapacitor and driving cycle in European countries.

A charge acceptance and discharged capability test is conducted for LAB coupled with supercapacitor [13]. The flaws of this study involve direct coupling of LAB with a supercapacitor without any DC/DC converter buffer. As a result of different characteristics of LABs and supercapacitors, this electrochemical storage system cannot be directly coupled to assess their performance. Although the hybridization of the supercapacitor and LAB is achieved in the work of [4], the percentage difference between the bus voltage and the LABs is more than $5 \%$, which remains a concern in terms of efficiency. 
Deu et al. [5] proposed a hybrid scheme of a LAB and supercapacitor; however, the study did not indicate a clear methodology for hybridization of the LAB and supercapacitor. In the works of $[14,15]$, a battery/supercapacitor hybrid is developed. In this design, the supercapacitor's function is to provide extra energy to the EV load that is required when the battery fails to deliver. The design is the result of the battery losing their performance over a prolonged period at peak demand operation. It is further emphasized that it is of paramount importance to employ decision-based control strategies for deciding when and how the electrochemical cells should be charged/discharged. However, the study focused on understanding the phenomenon of designing the battery-supercapacitor and driving cycle in European countries. Several topologies are used for the hybridization of LABs and supercapacitors. Sreedhar et al. [16] compared the different converter topologies for the LAB-supercapacitor hybrid.

The simulation claims that battery peak currents are reduced and a $40 \%$ increase in vehicle range is archived. The driving cycle (route) used to test the hybrid power system that is considered here is in the United States of America (USA), thus no other driving patterns where considered. A charge acceptance and discharged capability test is conducted for the LAB coupled with a supercapacitor [13]. The flaws of this study involve direct coupling of the LAB with a supercapacitor without any direct current-to-direct current (DC/DC) converter buffer. Because of differences in characteristics of LABs and supercapacitors, these electrochemical storage systems cannot be directly coupled to assess their performance. Two elements of energy management strategies are compared, which include optimization-based and rule-based strategy. The significance in both strategies is that the difference in current between the battery and supercapacitor is within $\pm 5 \%$ [17].

In the work of [18], hybridization of the LAB and supercapacitor is investigated without an electronic interface between the two energy storage devices. The aim was to deliver high peak current from the supercapacitor without affecting the LAB lifespan. However, the study did not indicate how good the agreement between the outputs of the LAB and supercapacitor are, and did not consider regenerative braking energy.

Therefore, this paper proposes a multi-stage LAB and supercapacitor hybrid system based on two direct current-to-direct current (DC/DC) converters for transport vehicles. This is done by using a simple proportional-plus-derivative-plus-integral (PID) controller as a control strategy on the converter to keep the batteries' SOC within limits. The PID control ensures that the batteries' output voltage and the reference voltage do not exceed $2 \%$ of the reference voltage. The battery SOC is kept between $90 \%$ and $95 \%$ and the voltage is kept at $12 \mathrm{~V}$, as shown in the results. LABs are prone to last longer if their SOC is kept above $50 \%$ and their terminal voltage does not go below $10 \mathrm{~V}$. This ensures that the battery is not deeply discharged, that is, below $50 \%$ SOC, which will reduce its lifespan significantly. The supercapacitor assists in absorbing the high current from the DC bus of the TV. Therefore, the dynamic control of keeping LABs' state-of-charge within limits is achieved in this paper, and terminal voltage is kept constant throughout the simulation.

This paper is organized as follows. Section 1 describes the related works, Section 2 outlines the methodology used, Section 3 presents the results and discussions, and Section 4 concludes the paper.

\section{Materials and Methods}

The possibility of hybridizing a lead acid battery with a supercapacitor has been widely studied in the work of [19], the hybridized system is said to provide huge energy capacity in small volumes and to enhance cold cranking capability in TVs. Although supercapacitors have high power density compared with LABs, they provide transient power during cold cranking at low temperatures. LABs are currently popular, however, at low temperatures, cold cranking is compromised in TVs at low SOC (i.e., below 50\%). Battery and supercapacitor models are studied using the simscape power system toolbox in Matrix Laboratory (MATLAB/Simulink). The use of the simscape simulation toolbox modeling for power systems design technology is suitable for evaluating the performance of energy storage systems for transport vehicles [20-22]. The approach is to design using a battery with parameters that are commercially available and study its behavior 
during the simulation. The developed architecture of the LAB and supercapacitor hybrid is simulated using MATLAB/Simulink. The topology used consists of two DC/DC boost converters for the LAB and a buck-boost for the supercapacitor. The buck-boost converter for the supercapacitor operates as a bi-directional power flow system. This allows the supercapacitor to accept current for both regenerative braking energy and powering the motor. The selected LAB has parameters indicated in Table 1 . The LAB's parameters are obtained from the commercially available valve regulated lead acid battery (VRLAB) used daily in the transport vehicles. The operating temperature is assumed to be at room temperature, as indicated. The supercapacitor's function is to absorb or provide transient currents during operation.

Table 1. Energy storage device parameters. SOC—state-of-charge.

\begin{tabular}{cc}
\hline Lead Acid Battery & Supercapacitor \\
\hline Output voltage $=12.2733 \mathrm{~V}$ & Rated Voltage $=12 \mathrm{~V}$ \\
Capacity $=75 \mathrm{Ah}$ & Rated Capacitance $=500 \mathrm{~F}$ \\
Initial SOC $=100 \%$ & Number of series capacitance $=6$ \\
Temperature $=25^{\circ} \mathrm{C}$ & Initial Voltage $=16 \mathrm{~V}$ \\
& Temperature $=25^{\circ} \mathrm{C}$ \\
\hline
\end{tabular}

The supercapacitor relieves the LAB from inrush current, which can shorten the batteries' lifespan significantly. The model developed in MATLAB/Simulink is represented by a flow diagram, as shown below in Figure 1.

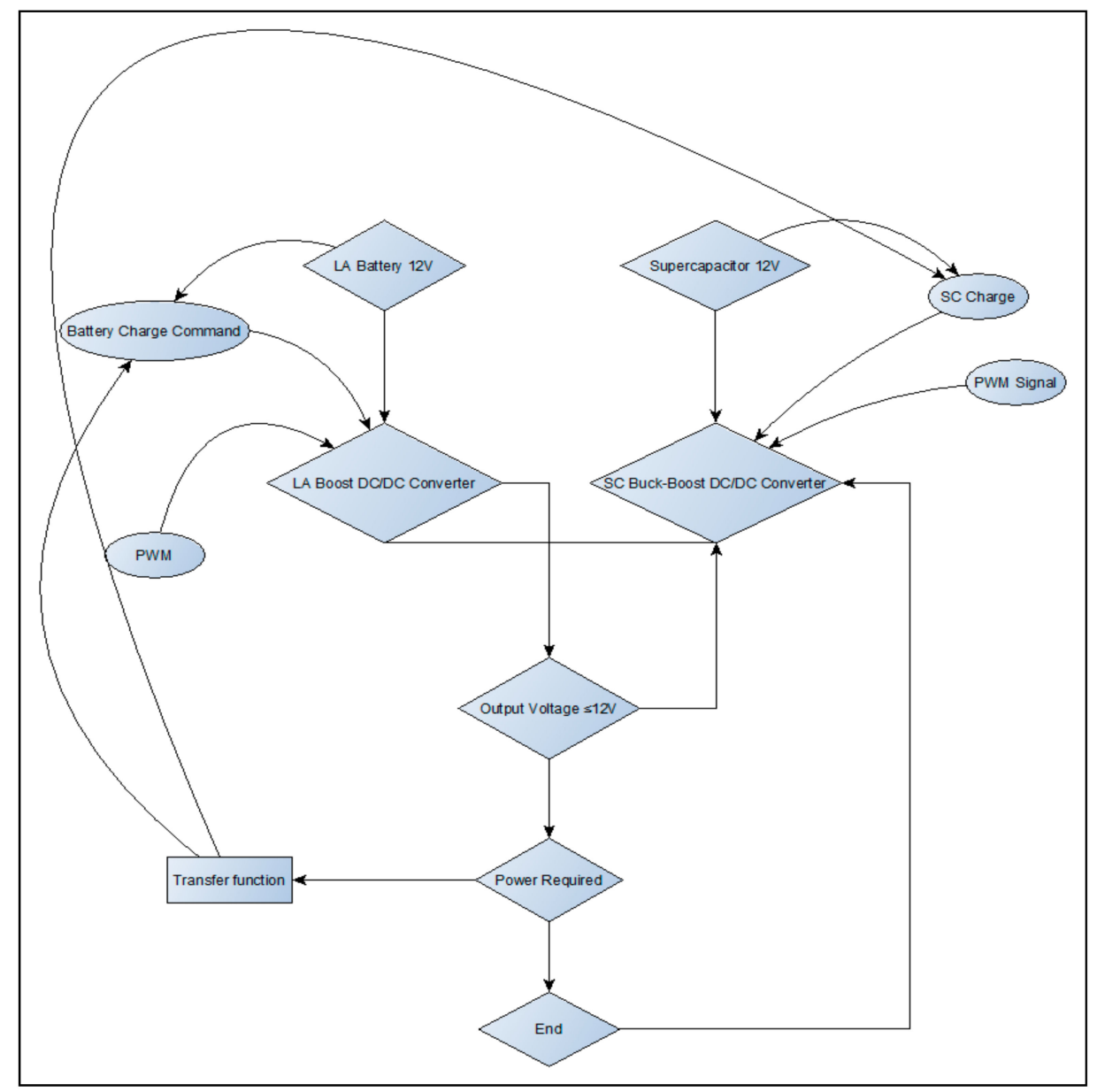

Figure 1. Matrix Laboratory (MATLAB)/Simulink lead acid battery (LAB)/supercapacitor hybrid system based on two direct current-to-direct current (DC/DC) converters. PWM-power width modulation. 
Figure 1 shows the LAB and supercapacitor hybrid system with two DC/DC converters connected in parallel to the DC bus. The current provided by both the LAB and supercapacitor are summed to the DC bus. Hence, from the DC bus, the transient currents are fed to the supercapacitor during regenerative braking, which relieve the battery from high peak currents. The typical power required for the system is discussed in the work of [23]. The battery converter ensures the battery SOC is kept within limits, whereas the supercapacitor converter ensures that the supercapacitor provides and absorbs high peak current to the DC bus of the transport vehicle.

\subsection{Lead Acid Battery}

The lead acid battery output includes voltage, current, and state-of-charge. The LAB voltage is controlled by the boost DC/DC converter, which is connected to the DC bus. The below formulae are used to determine the LAB's output characteristics:

$$
\begin{gathered}
\mathrm{SOC}=\frac{I_{\text {battery }}(t)}{3600 Q_{\text {battery }}} \\
I_{\text {battery }}=V_{o c} R_{\text {in.battery }} \\
E_{m}=\operatorname{Voc}-K_{e}\left(273+T_{b}\right)(1-\mathrm{SOC})
\end{gathered}
$$

where SOC is the battery state-of-charge, $I$ is the battery current, and $Q$ is the battery charge from Equation (1). Consequently, from Equation (2), Voc is the battery open circuit voltage and Rin is the battery internal resistance. Lastly, from Equation (3), Em is the electromotive energy, Ke is the electron constant, and $T b$ is the operating temperature.

The LAB boost DC/DC converter is represented by a flow diagram as shown below in Figure 2 . The converter is controlled based on power width modulation (PWM) of saw tooth signal. The battery voltage is controlled using a PID, which regulates the battery SOC. The saw tooth signal generator of a power width modulator is generated from the specialized technology in control and measurement library under the generator of different signals. The PWM generates a saw tooth waveform, with peak values between +1 and -1 . The output of the generator is specified as a time value pair for the simulation. Consequently, the PID controller is implemented as a continuous time domain. The derivative of this controller is set to zero and connected in parallel. Figure 2 below illustrates the control strategy of the LAB's boost DC/DC converter for ensuring a stable DC output voltage as compared with the reference PWM signal value. Also, Figure 3 below shows that the initial conditions for this controller are set to execute from external variables, have a zero crossing detection functionality, and have a compensation that is represented by Equation (4). The output of the PID controller is limited to an upper and lower limit of \pm 1 and treats it as a gain during linearization by the saturation block. The battery characteristics are shown in Figure 4.

$$
\rho=P+I \frac{1}{s}+D \frac{N}{1+N \frac{1}{s}}
$$

where $\rho$ is the compensation of the PID control. 


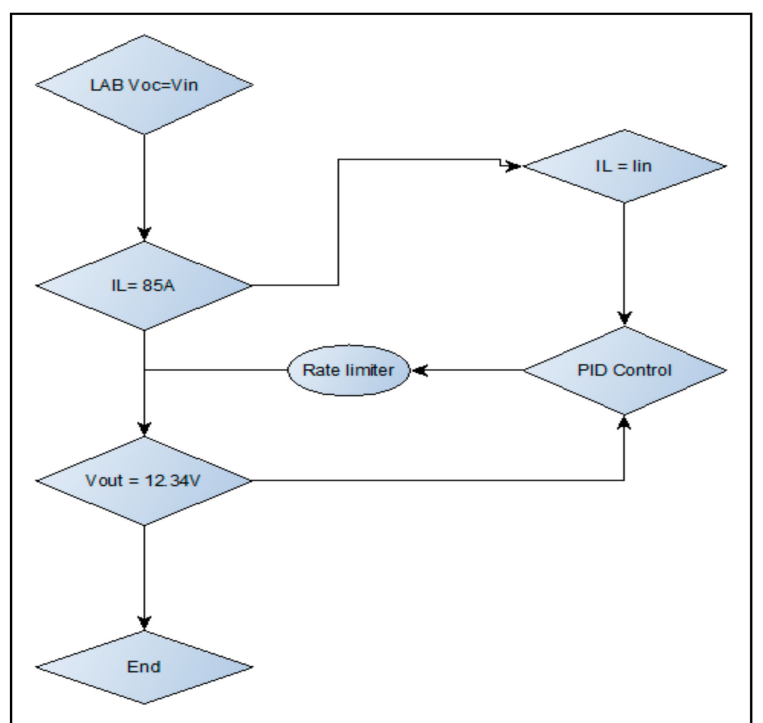

Figure 2. Boost DC/DC converter for the LAB and control strategy. PID—proportional-plus-derivativeplus-integral.

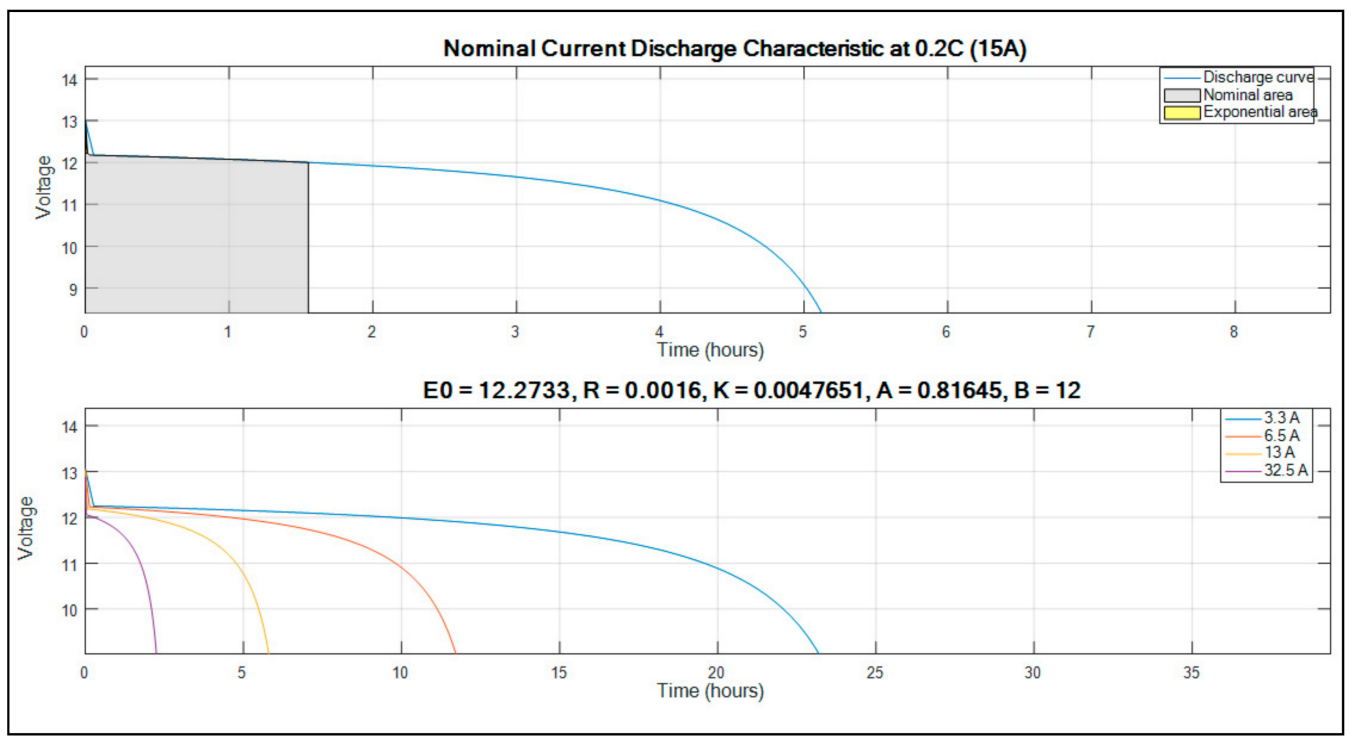

Figure 3. Modelled LAB characteristics.

The selected battery characteristics are shown in the plotted graph of Figure 3 below.

The graph showing the normal current discharge characteristics indicate that for this particular selected battery, it takes $5.2 \mathrm{~h}$ to reach a voltage of $0 \mathrm{~V}(\mathrm{SOC}=0 \%)$ if it is discharged at $0.2 \mathrm{C}(15 \mathrm{~A})$. The C-rate is defined as the Ampere or milli-ampere rate, which is numerically equal to the capacity rating of the cell and represented in Ah or mAh. The battery operates under normal conditions between 0 and $1.5 \mathrm{~h}$ of the time. Moreover, the graph showing several constants indicates that initially, the battery is at $100 \% \mathrm{SOC}$, and if it is discharged, it is discharged at a different current. Also, the graph indicates the requirement for changing the battery if the LAB is defective (operating conditions factors). The assumed current values are indicated on the legend of the graph. The selected battery has the following parameters:

- Open circuit voltage of $12.2733 \mathrm{~V}$.

- Internal Resistance of $0.0016 \Omega$.

- $\quad$ Performance factors $K$ of $0.0047651, A$ of 0.81645 , and $B$ of 12 . 
This indicates that the battery lasts for $24 \mathrm{~h}$ if it is discharged at $3.3 \mathrm{~A}$, which is the lowest in the analysis carried out.

The battery was tested at a nominal constant discharge current of $15 \mathrm{~A}(0.2 \mathrm{C})$ for $8 \mathrm{~h}$ under a normal operating temperature of $\pm 25^{\circ} \mathrm{C}$. The voltage in time domain was recorded and the results were plotted as illustrated in Figure 3 (top graph). Consequently, different discharge current of $32.5 \mathrm{~A}$, $13 \mathrm{~A}, 6.5 \mathrm{~A}$, and $3.5 \mathrm{~A}$ were applied in order to evaluate the LAB characteristics, which included open circuit voltage; internal resistance; and $K, A$, and $B$ factors, as illustrated in Figure 3 above (bottom graph).

The open circuit voltage is measured and is found to be $12.2733 \mathrm{~V}$, as indicated above in Figure 3.

The charging and discharging cycle methodology approach considered for this typical LAB is constant-current-constant-voltage (CCCV) charging. Although overcharge is of great concern for this methodology approach, it can easily be controlled, unlike in constant voltage charging. Under the constant voltage charging, undercharging is of primary concern with these algorithms, and it is difficult to maneuver within the problem.

\subsection{Supercapacitor}

The supercapacitor used in the study is an electro double layer capacitor (EDLC) and is modelled such that it consists of similar output to that of the LAB, which consists of the terminal voltage, current, and the SOC. The supercapacitor model, the buck-boost DC/DC converter with control, is signified by a flow diagram as shown in Figures 4 and 5 below. The supercapacitor discharge characteristics are also shown. The outputs of the supercapacitor are determined according to the following formulae:

$$
\begin{gathered}
V s c(t)=V i e^{\left(-\frac{t}{R C}\right)} \\
I_{s c}=\frac{P_{s c}}{V_{s c}} \\
S O C=\mathrm{SOC}_{0}-\int_{0}^{t} \frac{\epsilon_{f} I}{Q} d t
\end{gathered}
$$

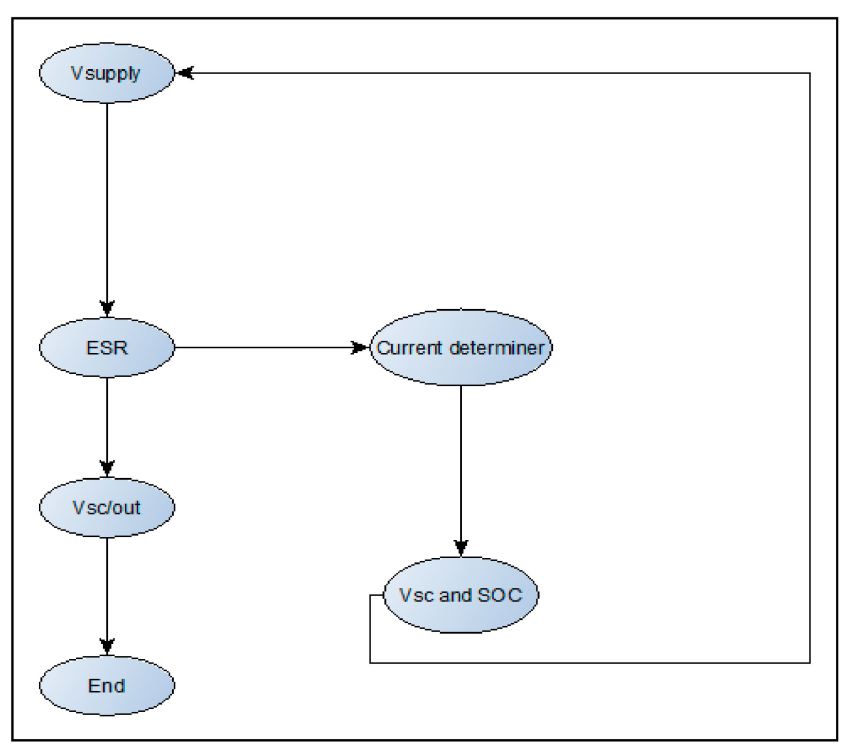

Figure 4. Supercapacitor model developed in MATLAB/Simulink.

The supercapacitor model demonstration shown in Figure 4 is modelled using an equivalent circuit model as described in the works of [24]. The voltage of the supercapacitor is obtained using a controlled voltage source, which is connected to the continuous model for derivation of 
the supercapacitor's SOC and current. The equivalent DC series resistance is assumed to be ideal. The continuous model developed for determining the supercapacitor's SOC and current includes the summation block for connecting the output of the multiplier and the self-discharge model characteristics, thus integrating the output of the summation added to the initial charge of the supercapacitor (which reflects the formulation of SOC and current). The control strategy of the supercapacitor buck-boost DC/DC converter is described with a flow diagram in Figure 5 below, which complements the Simulink model signified by a flow diagram shown in Figure 6.

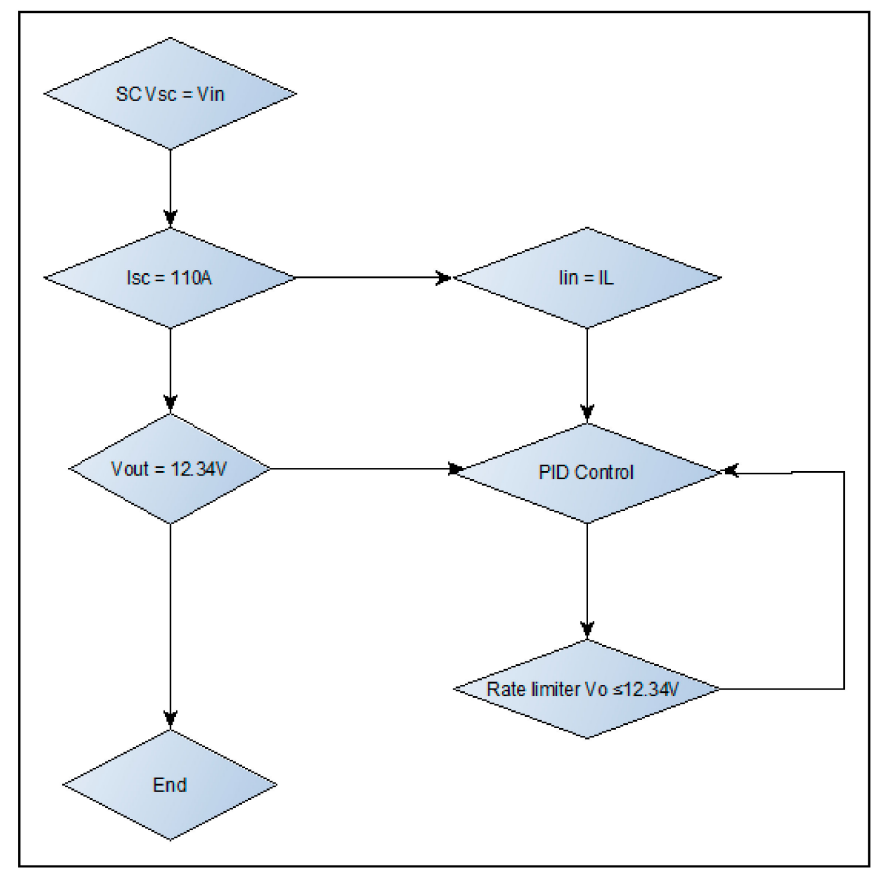

Figure 5. Control strategy of the buck-boost controller for the supercapacitor.

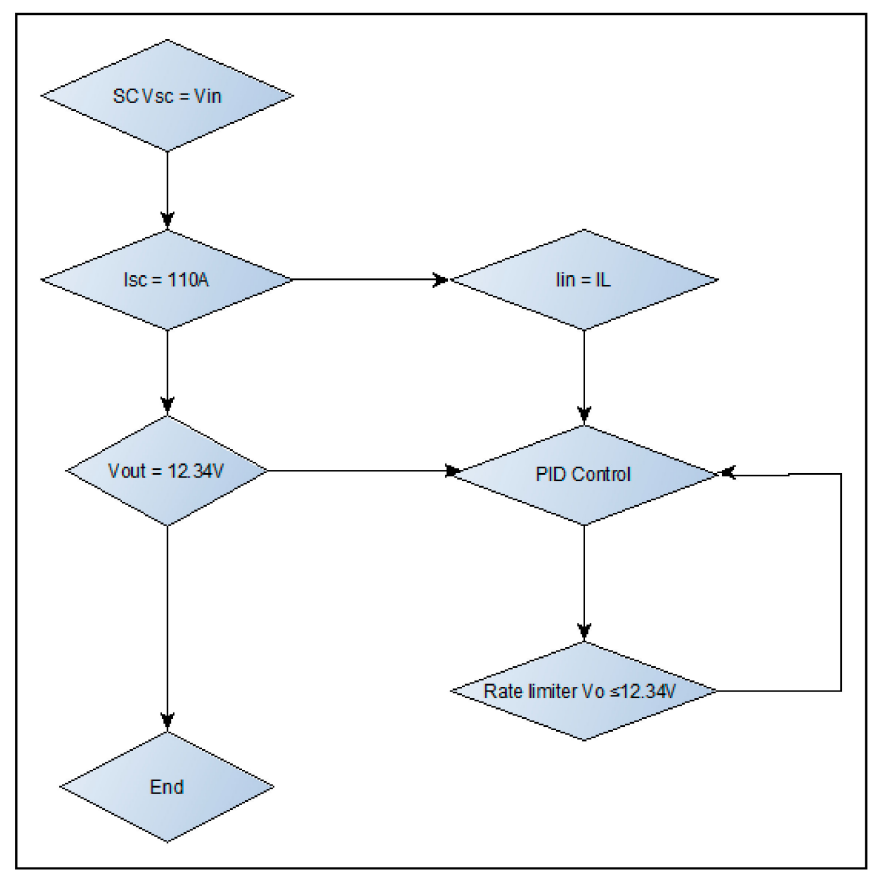

Figure 6. Buck-boost DC/DC converter for the supercapacitor control. 
The buck-boost converter developed for the supercapacitor shown in Figure 6 consists of two ideal insulated gate bipolar transistors (IGBTs) to control the current flowing to and from the DC bus. The switching mechanism of these switches is assumed to be ideal. The PID controller of the converter controls the current and the reference current to the supercapacitor. The PID operates in continuous mode and the developed form operates in parallel; it also has in internal source and uses the similar equation of compensation as described in Equation (4). The output of the PID controller is limited to \pm 1 by the saturation block compared with the PWM signal to be the same as or less than the limited value. The converter is developed to have bi-directional power flow (current) to absorb and provide high transient currents for acceleration and regenerative braking purposes.

The graph showing the supercapacitor characteristics is shown in Figure 7.

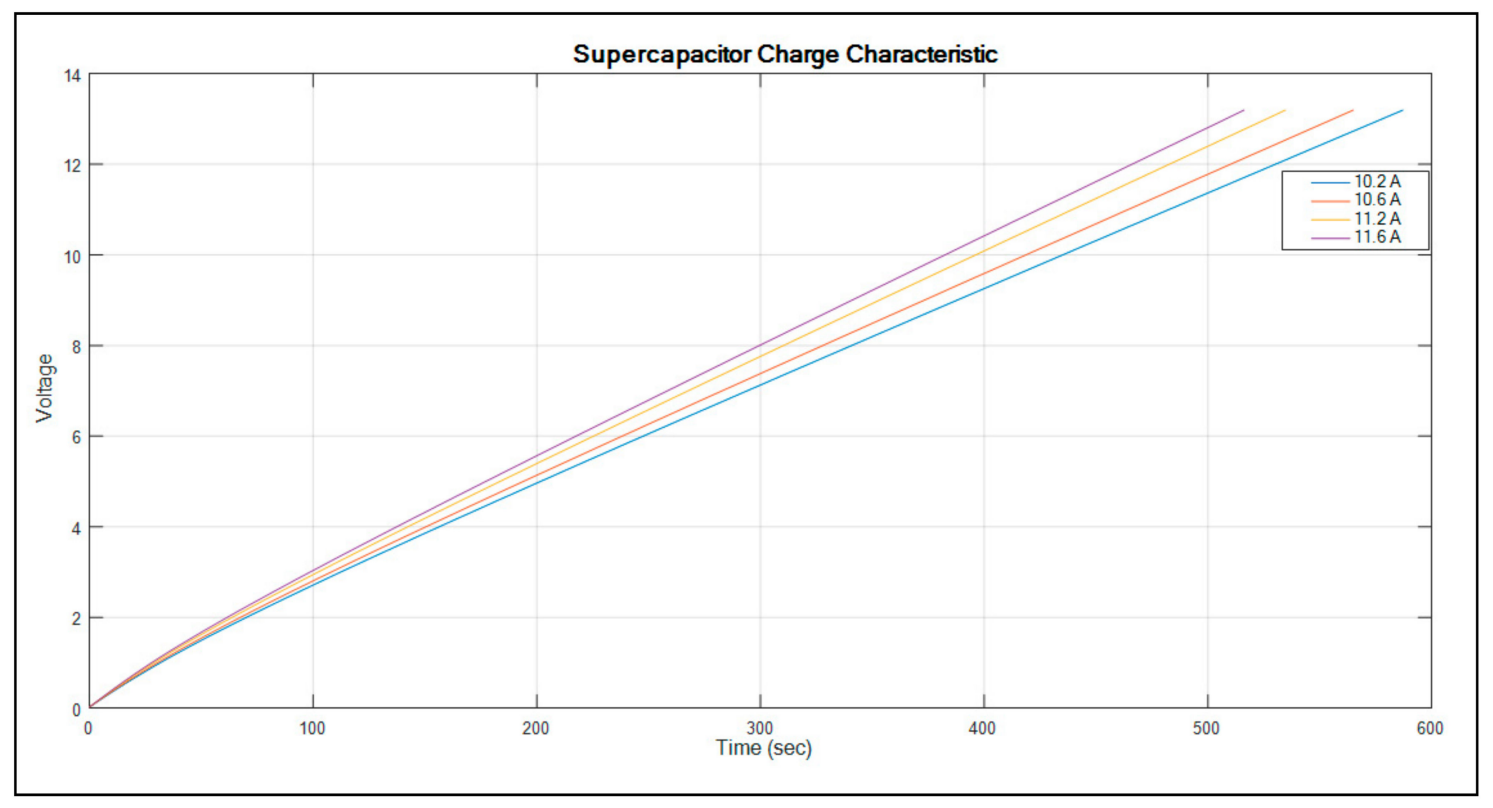

Figure 7. Supercapacitor charge characteristics at 10.2 Ampere.

Figure 7 shows the supercapacitor voltage versus time, which indicates the supercapacitor charge characteristics. The graph indicates the current size used to charge the supercapacitor and will determine the time it will take to reach $100 \%$ SOC. The higher the current, the shorter the time it takes to fully charge the supercapacitor. In order to charge this particular supercapacitor in less than $520 \mathrm{~s}$, it needs a current of 11.6 A or higher.

The simulation procedure of the modelled system is shown by the flow diagram in Figure 8 below.

As shown in Figure 8, the LAB and the EDLC supercapacitor are connected to their individual DC/DC converter. These converters are then connected in parallel to produce similar output. The output power produced by both the supercapacitor and LAB is compared and merged to the defined required power of a typical transport vehicle, as previously mentioned. Both the power converters consist of an individual PID controller for reliable control of individual energy storage systems in order to control the input and output parameters. Moreover, a similar PWM signal generator is connected to each converter. The signal generator's function is to gate the IGBT switches for quality control and operation of the converters. The voltage output of the converters is compared with the vehicle DC bus voltage. Consequently, the system evaluates the EDLC terminal voltage, current, and SOC. The LAB's terminal voltage, current, and SOC are also monitored during the simulation. The simulation is debugged and ran for a period of $350 \mathrm{~s}$, because the computer memory was not enough to simulate for a period more than $350 \mathrm{~s}$. Despite the computer memory, the simulation took more than $3 \mathrm{~h}$ to complete. The unprocessed simulation results are obtained and saved in a MATLAB format known as workspace for further processing. 


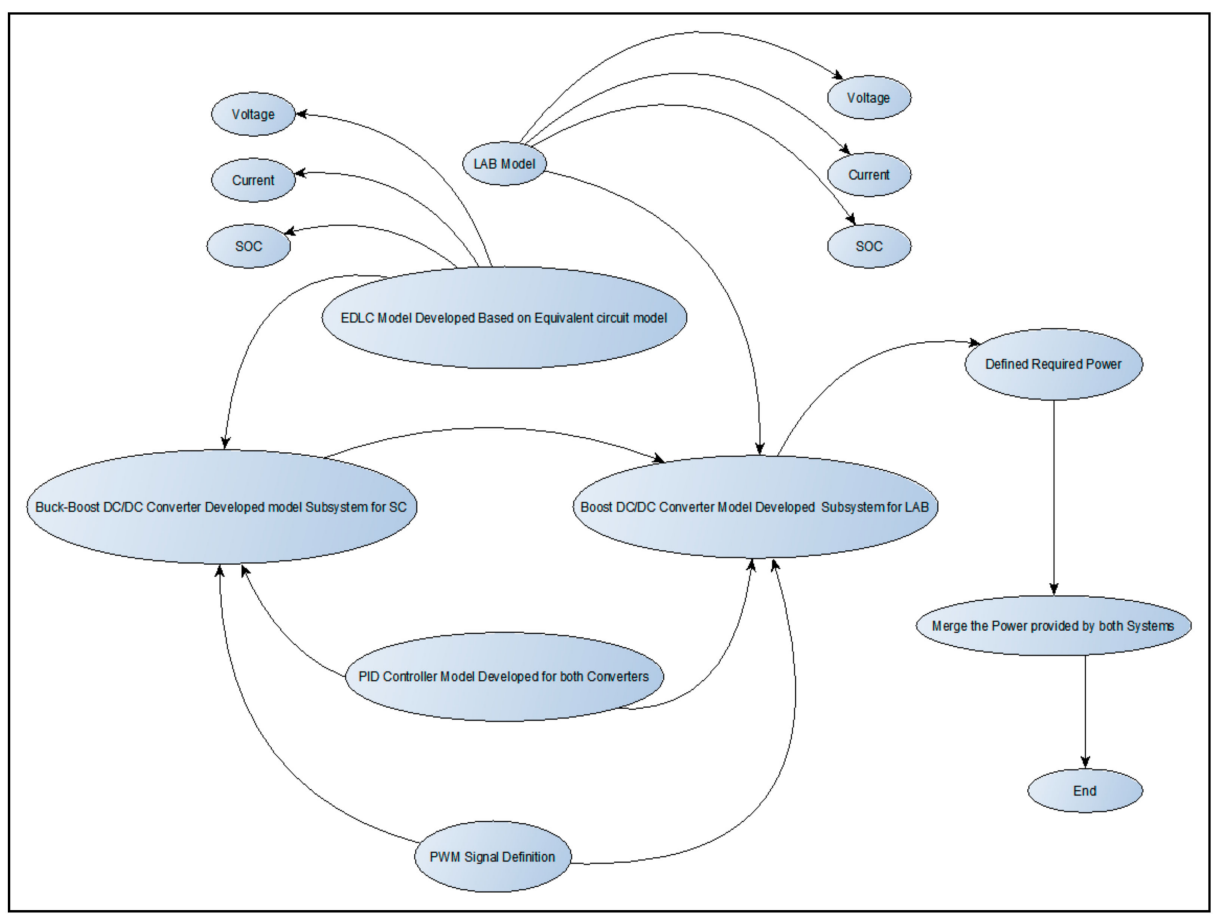

Figure 8. Describes the simulation procedure of the developed model. EDLC-electro double layer capacitor.

\section{Results and Discussion}

The simulation of the results was performed using MATLAB/Simulink on a Lenovo Laptop computer with 6 GB Random Access Memory (RAM) with a 64-bit operating system. Hence, in order to ensure that the battery and supercapacitor hybrid system operates satisfactorily, a typical hybrid electric vehicle was used, which is equipped with a $2 \mathrm{~kW}$ motor. The required current for the typical hybrid electric vehicle is compared with current produced by the LAB and supercapacitor. Consequently, the LAB's SOC and voltage are kept within $90-96 \%$ and $12 \mathrm{~V}$, respectively. Moreover, the SOC of the LAB and supercapacitor is also evaluated in this simulation study.

The graph showing the voltage versus time of the LAB and supercapacitor is plotted in Figure 9.

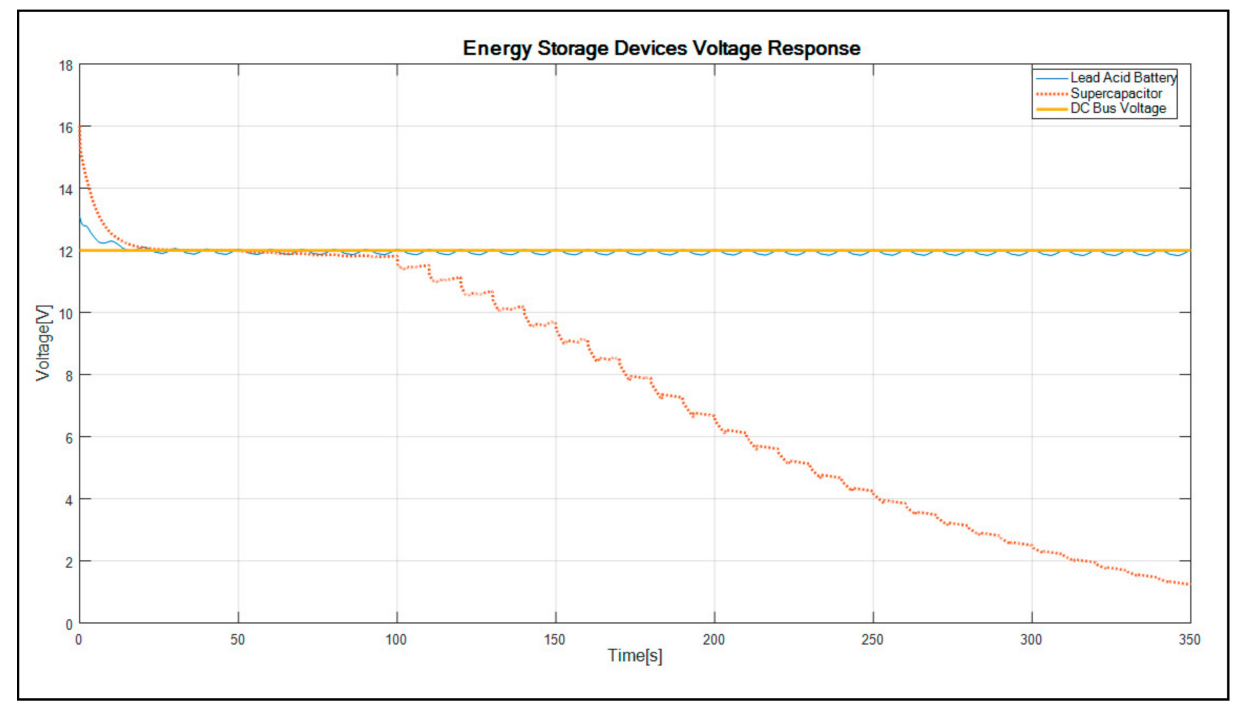

Figure 9. LAB and supercapacitor voltage response. 
As shown in Figure 9, the lead acid battery and supercapacitor show a decreasing dynamic voltage response between $0 \mathrm{~s}$ and $30 \mathrm{~s}$ when the current is supplied to the DC bus. Thereafter, the voltage of the LAB becomes constant for the duration of the simulation, whereas the supercapacitor voltage continues to decrease close to zero after $100 \mathrm{~s}$ of the simulation. The voltage of the LAB resonates at $12 \mathrm{~V}$, which describes better balance battery voltage as described in the work of [25]. When compared with the supercapacitor's voltage, the results indicate the dynamic descending response at the beginning of the simulation, whereby after $30 \mathrm{~s}$, the supercapacitor's voltage merged with the LAB's voltage. As a result of the supercapacitor being unable to hold a charge for a long duration, it is clear from the results that the voltage reached less than $4 \mathrm{~V}$ from $15.5 \mathrm{~V}$. There is $1.6 \%$ change in the LAB's voltage, which offers better system performance as compared with the illustrated topology in the literature [21,26,27].

The plotted graph showing the delivered average current by the LAB and supercapacitor is shown in Figure 10.

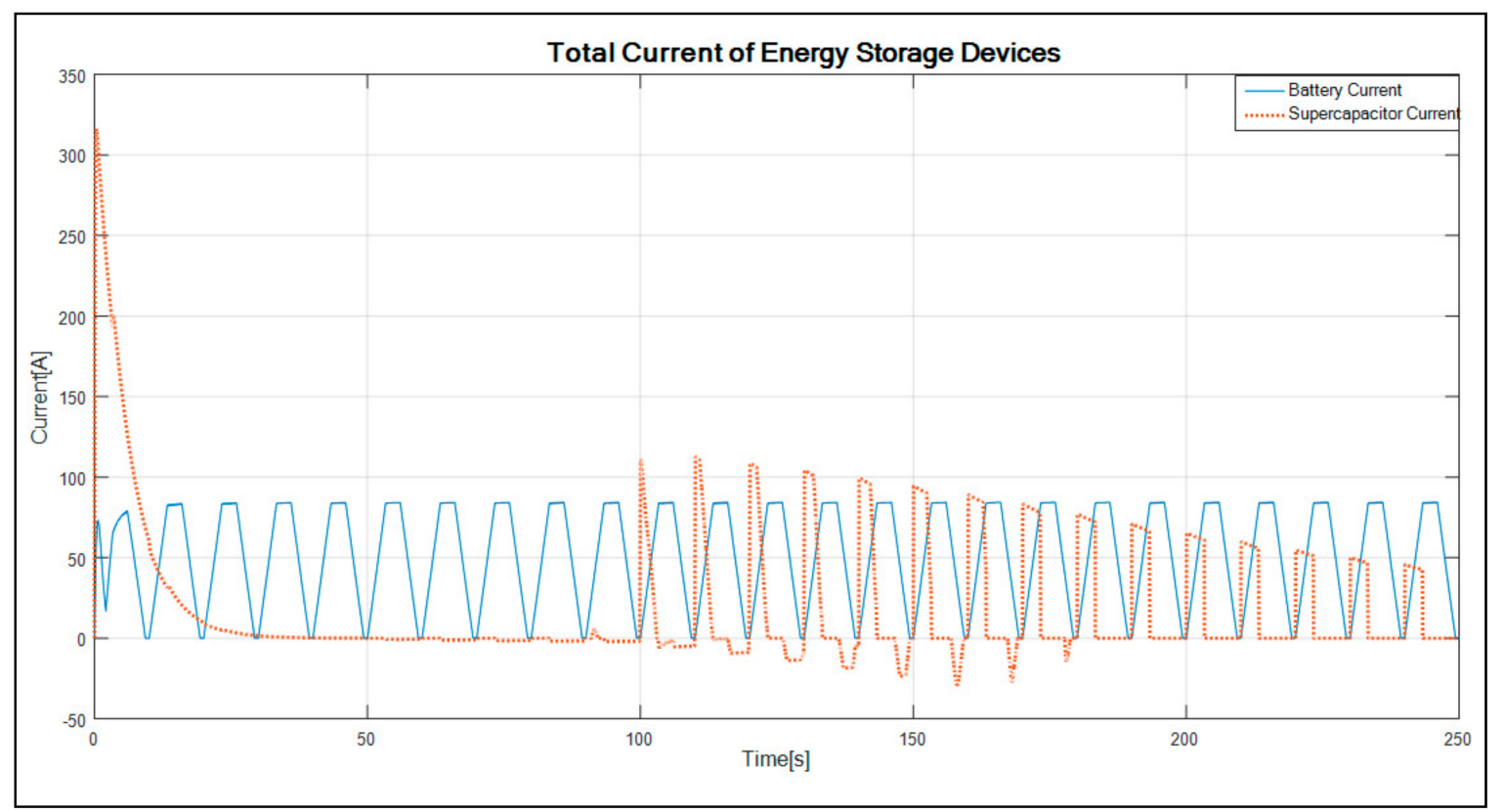

Figure 10. LAB/supercapacitor hybrid current produced by individual Energy Storage Device.

As shown in Figure 10, the supercapacitor shows a dynamic decrease response of current between $0 \mathrm{~s}$ and $35 \mathrm{~s}$ of the simulation; thereafter, the current is zero until $100 \mathrm{~s}$ of the simulation. Hence, the supercapacitor begins charging for the remaining duration of the simulation and reaches the maximum of $110 \mathrm{~A}$ from $13.4 \mathrm{~A}$. Consequently, the LAB supplies a more stable current of about $55 \mathrm{~A}$ from the initial point to the end of the simulation results. The current delivery from both energy storage devices to the DC bus is close to $165 \mathrm{~A}$. The battery indicates a stable current delivery of approximately $98 \mathrm{~A}$ and that of the supercapacitor fluctuated and reached a maximum of 110 A over the simulation period. The fluctuation is caused by charging/discharging of the device. For a $2 \mathrm{~kW}$ motor, both the devices can meet the motor current demand at a DC bus voltage of $12 \mathrm{~V}$. There is a better stability of current provided by the battery, making this topology a better approach system compared with the current variables provided to the described topology results in the literature [22,28,29].

The graph describing the power delivered by the LAB and supercapacitor compared with the typical required vehicle power versus time is shown in Figure 11. 


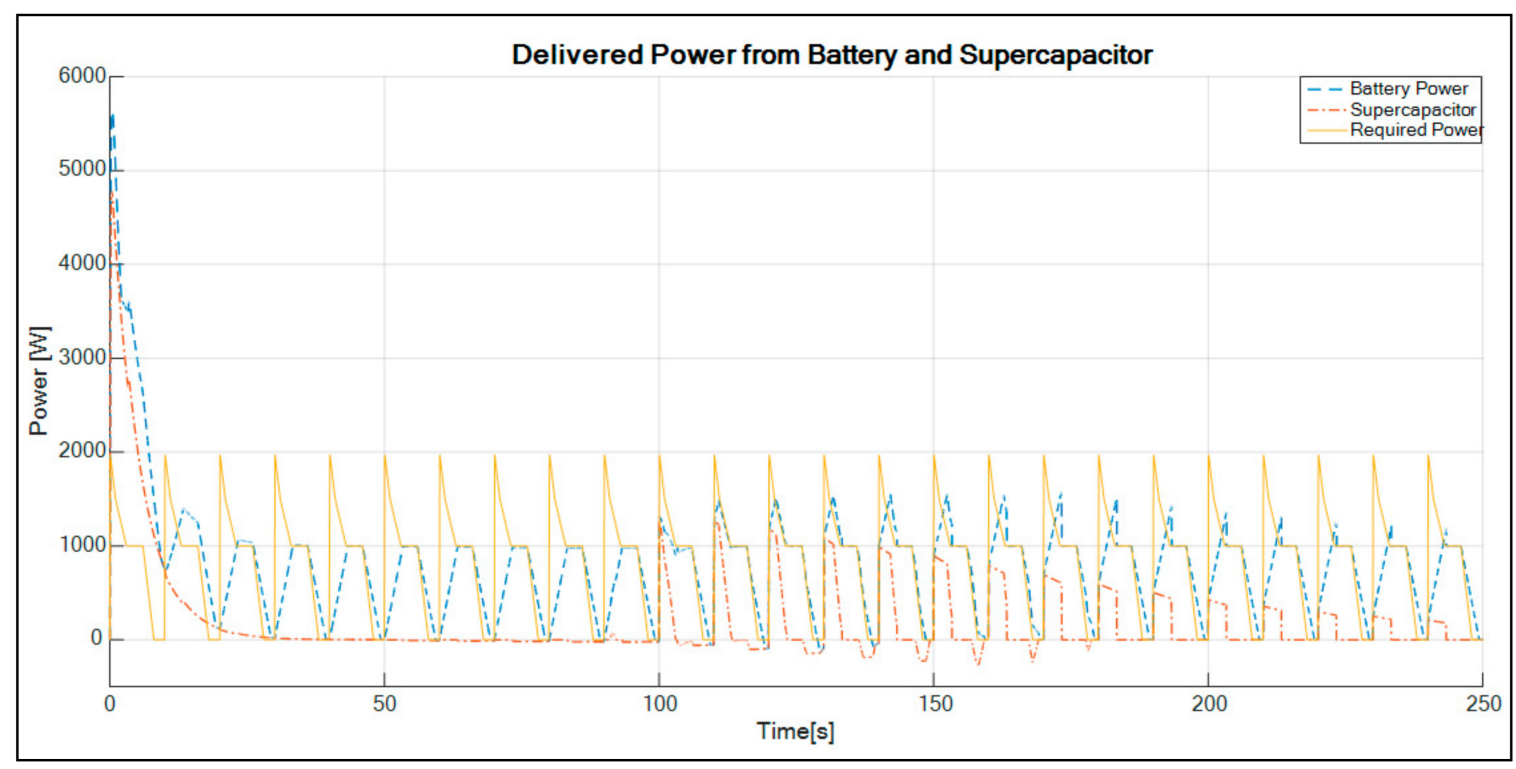

Figure 11. Typical power delivered by the LAB/supercapacitor hybrid system versus the required power of the hybrid transport vehicle.

As shown in Figure 11, there is a significant dynamic decrease response of the power delivered to the TVs within the first $25 \mathrm{~s}$ of the simulation. This is because of the high required starting power for a typical hybrid system, which is more than twice the required power. The battery alone is incapable of delivering the required power of a typical hybrid transport vehicle. With the addition of the supercapacitor, the results show that the $\mathrm{LAB}$ and supercapacitor can be connected and deliver the required power to the TV. The behavior of the LAB and supercapacitor demonstrating a dynamic response of high power at the beginning can indicate the energy storage device initial SOC and can be used to satisfy the hybrid TV demand. It can be seen that in the event where the supercapacitor is unable to supply the power to the TV, the battery is providing the average power required. There is $9 \%$ extra power delivered by the system, making it a better hybrid topology compared with the topologies illustrated in the works of [30,31].

The results of the simulation topology are summarized in Table 2 below.

Table 2. Mean results of supercapacitor and lead acid battery (LAB) power, voltage, current, and state-of-charge (SOC).

\begin{tabular}{cccccccc}
\hline $\begin{array}{c}\text { SC Power } \\
(\mathbf{W})\end{array}$ & $\begin{array}{c}\text { LAB Power } \\
(\mathbf{W})\end{array}$ & $\begin{array}{c}\text { SC Current } \\
(\mathbf{A})\end{array}$ & $\begin{array}{c}\text { LAB Current } \\
(\mathbf{A})\end{array}$ & $\begin{array}{c}\text { SC Voltage } \\
(\mathbf{V})\end{array}$ & $\begin{array}{c}\text { LAB Voltage } \\
(\mathbf{V})\end{array}$ & $\begin{array}{c}\text { SC SOC } \\
(\mathbf{\%})\end{array}$ & $\begin{array}{c}\text { LAB SOC } \\
(\%)\end{array}$ \\
\hline 114.7985 & 779.9167 & 13.4772 & 55.8535 & 7.9157 & 11.9350 & 58.1388 & 96.9880 \\
\hline
\end{tabular}

As described in Table 2 above, the results indicate that the battery SOC and voltage are kept within the statistical limits of $97 \%$ and $12 \mathrm{~V}$, respectively. Keeping the battery voltage and SOC at this limits enhances the battery lifespan. Therefore, the topology ensures that the battery is not over/under charged at any circumstances of the simulation.

The plotted graph showing the battery and supercapacitor SOC versus time is shown in Figure 12. 


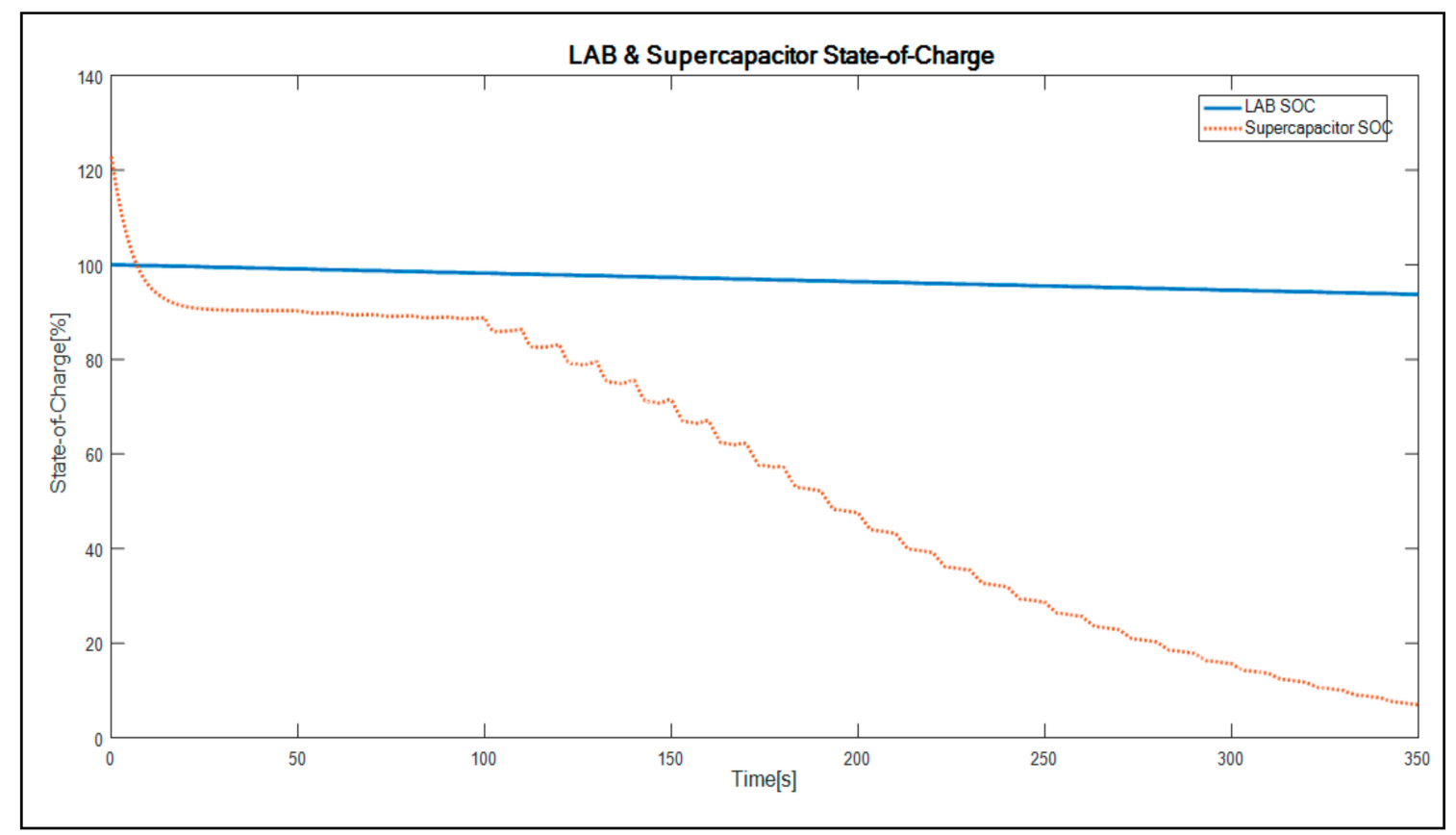

Figure 12. Lead acid battery state-of-charge and supercapacitor state-of-charge response.

As shown in Figure 12, the lead acid battery SOC reduces by up to $95 \%$ or less, and keeps resonating at $96 \%$ for the duration of the simulation. This stipulates that the battery is kept at a good SOC limit, as does not reduce to less than $50 \%$. Consequently, the supercapacitor SOC is stable at between $95 \%$ and $100 \%$ for $100 \mathrm{~s}$ of the simulation study and thereafter, begins to drop as it discharges. Therefore, the supercapacitor discharges all the energy and recharges for the next cycle.

The converter algorithm of LAB keeps the battery state-of-charge at $96 \%$. This ensures that the battery is not deeply discharged during operation. The voltage is kept as constant as possible at $12 \mathrm{~V}$. This ensures that the battery is not stressed and allows a minimum current to flow through the battery for the charging algorithm. When compared with the supercapacitor, it allows high currents to flow through it. The supercapacitor characteristic of having more than 1000 cycles for charge/discharge allows it to save the battery for deep cycles, hence allowing the battery to have endured an enhanced lifespan.

Based on the results, the proposed hybrid system provides better battery terminal voltage stability for a prolonged period, as well as the battery SOC. Although the battery SOC is kept high enough, this causes the battery to have a low charge acceptance. Hence, all the excess energy during regenerative braking can be stored by the supercapacitor. The system is easier to implement than the complex control methodology used in the described references. The system enhances battery lifespan significantly by controlling the battery terminal voltage and SOC, thus keeping it at high statistical limits of $12 \mathrm{~V}$ and $96 \%$, respectively.

\section{Conclusions}

The lead acid battery life is highly affected by the way it is charged or discharged. The charging/discharging algorithm for a LAB is developed, and indicated that keeping the battery state-of-charge above $50 \%$ from $0 \%$ can positively increase the battery lifespan by connecting the supercapacitor in parallel. The simulation is based on a MATLAB/Simulink environment. A typical hybrid vehicle can be powered by the use of a lead acid battery and supercapacitor interfaced by the power electronic DC / DC converter. Therefore, using the topology described in the methodology, the LAB lifespan can be significantly increased with the supercapacitor. Furthermore, the hybrid is controlled by a simple algorithm that does not require complex behavioral studies. Therefore, keeping the LABs charge acceptance low forces all the transient currents to be absorbed by the supercapacitor, 
and hence reduces the stress to the battery. Reduction of battery stress provides an enhanced battery lifespan in due course.

Author Contributions: Conceptualization, S.P.C., M.J.L. and T.O.O.; Methodology, M.J.L., S.P.C. and T.O.O.; Software, M.J.L. Validation, M.J.L., S.P.C. and T.O.O.; Formal Analysis, M.J.L.; Investigation, M.J.L.; Resources, S.P.C. and M.J.L.; Data Curation, M.J.L.; Writing-Original Draft Preparation, M.J.L.; Writing-Review \& Editing, M.J.L., T.O.O. and S.P.C.; Visualization, S.P.C., M.J.L. and T.O.O.; Supervision, S.P.C. and T.O.O.; Project Administration, S.P.C., T.O.O. and M.J.L.; Funding Acquisition, S.P.C. and T.O.O.

Funding: This research received no external funding.

Acknowledgments: The authors would like to thankfully acknowledge the contributions of the Tshwane University of Technology, Pretoria and the Auto-X (Pty) Ltd., Port Elizabeth for providing necessary infrastructure to conduct this research study.

Conflicts of Interest: The authors declare no conflict of interest.

\section{Nomenclature}

Describes the nomenclature used

\begin{tabular}{ll} 
DC & Direct Current \\
DC/DC & Direct Current-to-Direct Current \\
EDLC & Electric Double Layer Capacitor \\
EVs & Electric Vehicles \\
HESS & Hybrid Energy Storage System \\
HEVs & Hybrid Electric Vehicles \\
IGBTs & Insulated Gate Bipolar Transistors \\
LABs & Lead Acid Batteries \\
MATLAB/Simulink & Matrix Laboratory \\
PHEVs & Plug-in Hybrid Electric Vehicles \\
PID & Proportional plus Integral plus Derivative \\
PWM & Power Width Modulation \\
RAM & Random Access Memory \\
SOC & State-of-Charge \\
TVs & Transport Vehicles \\
VRLABs & Valve Regulated Lead Acid Batteries \\
Describes the mathematical expressions used in this paper \\
$E_{m}$ & Battery Electromotive Energy \\
$I_{b a t t e r y}(t)$ & Battery current as function of time \\
$I_{s c}$ & Supercapacitor current \\
$K_{e}$ & Electron constant \\
$K, A \& B$ & Battery performance factors \\
$P_{s c}$ & Supercapacitor power \\
$\rho$ & PID compensation factor \\
$Q_{b a t t e r y}$ & Battery charge \\
$Q$ & Charge \\
$R_{\text {in.battery }}$ & Battery internal resistance \\
$R C$ & Resistance and capacitance \\
$T_{b}$ & Battery operating temperature \\
$V_{o c}(t)$ & Open circuit voltage as a function of time \\
$V_{s c}(t)$ & Supercapacitor voltage as a function of time \\
& \\
\hline &
\end{tabular}




\section{References}

1. Camara, M.B.; Gualous, H.; Gustin, F.; Berthon, A. Design and New Control of DC/DC Converters to Share Energy Between Supercapacitors and Batteries in Hybrid Vehicles. IEEE Trans. Veh. Technol. 2008, 57, 2721-2735. [CrossRef]

2. Al Sakka, M.; Gualous, H.; Omar, N. Batteries and Supercapacitors for Electric Vehicles. In New Generation of Electric Vehicles; InTech: London, UK, 2012; pp. 135-164.

3. Stienecker, A.W.; Stuart, T.; Ashtiani, C. A combined ultracapacitor-Lead acid battery energy storage system for mild hybrid electric vehicles. IEEE Veh. Power Propuls. Conf. 2005, 2005, 350-355.

4. Hatwar, N.; Bisen, A.; Dodke, H.; Junghare, A.; Khanapurkar, M. Design approach for electric bikes using battery and super capacitor for performance improvement. IEEE Conf. Intell. Transp. Syst. Proc. 2013, 1959-1964. [CrossRef]

5. Batteries, Supercapacitors, Alternative Storage for Portable Devices 2009-2019. IDTechEx, 15-Apr-2009. Available online: https://www.idtechex.com/research/reports/batteries_supercapacitors_alternative_ storage_for_portable_devices_2009_2019_000224.asp (accessed on 9 October 2018).

6. Miller, D.J.; Technologies, M. Power Electronic Interface for an Ultracapacitor as the Power Buffer in a Hybrid Electric Energy Storage System. 2012. Available online: https:/ /www.maxwell.com/images/documents / whitepaper_powerelectronicsinterface.pdf (accessed on 9 October 2018).

7. Dai, H.; Chang, X. A study on lead acid battery and ultra-capacitor hybrid energy storage system for hybrid city bus. Int. Conf. Optoelectron. Image Process. 2010, 1, 154-159. [CrossRef]

8. Song, Z.; Hou, J.; Hofmann, H.; Li, J.; Ouyang, M. Sliding-mode and Lyapunov function-based control for battery/supercapacitor hybrid energy storage system used in electric vehicles. Energy 2017, 122, 601-612. [CrossRef]

9. Fernão Pires, V.; Romero-Cadaval, E.; Vinnikov, D.; Roasto, I.; Martins, J.F. Power converter interfaces for electrochemical energy storage systems-A review. Energy Convers. Manag. 2014, 86, 453-475. [CrossRef]

10. Hossain, M.Z.; Rahim, N.A.; Selvaraj, J. Recent progress and development on power DC-DC converter topology, control, design and applications: A review. Renew. Sustain. Energy Rev. 2018, 81, 205-230. [CrossRef]

11. Nguyen, A.; Lauber, J.; Dambrine, M. Optimal control based algorithms for energy management of automotive power systems with battery/supercapacitor storage devices. Energy Convers. Manag. 2014, 87, 410-420. [CrossRef]

12. Hannan, M.A.; Azidin, F.A.; Mohamed, A. Multi-sources model and control algorithm of an energy management system for light electric vehicles. Energy Convers. Manag. 2012, 62, 123-130. [CrossRef]

13. Ferg, E.; Rossouw, C.; Loyson, P. The testing of batteries linked to supercapacitors with electrochemical impedance spectroscopy: A comparison between Li-ion and valve regulated lead acid batteries. J. Power Sources 2013, 226, 299-305. [CrossRef]

14. Kouchachvili, L.; Yaïci, W.; Entchev, E. Hybrid battery/supercapacitor energy storage system for the electric vehicles. J. Power Sources 2018, 374, 237-248. [CrossRef]

15. Vulturescu, B.; Butterbach, S.; Forgez, C.; Coquery, G.; Friedrich, G. Ageing study of a supercapacitor-battery storage system. Int. Conf. Electr. Mach. 2010, 1-6. [CrossRef]

16. Sreedhar, S.; Siegel, J.B.; Choi, S. Topology Comparison for 48V Battery-Supercapacitor Hybrid Energy Storage System. IFAC-PapersOnLine 2017, 50, 4733-4738. [CrossRef]

17. Castaings, A.; Lhomme, W.; Trigui, R.; Bouscayrol, A. Comparison of energy management strategies of a battery/supercapacitors system for electric vehicle under real-time constraints. Appl. Energy 2016, 163. [CrossRef]

18. Fiorenti, S.; Guanetti, J.; Onori, S.; Guezennec, Y.; Madella, N.; Saletti, A.; Bovo, S. Modeling and Experimental Validation of PbA Battery-Supercapacitor Energy Storage System? IFAC: New York, NY, USA, 2013.

19. Liu, H.; Maly, D.; Wang, Z. Supercapacitor and lead-acid battery hybrid and improved diesel engine cold cranking. IET Conf. Publ. 2008, 199-203. [CrossRef]

20. Infante, W.F.; Khan, A.F.; Libatique, N.J.C.; Tangonan, G.L.; Uy, S.N.Y. Performance evaluation of series hybrid and pure electric vehicles using lead-acid batteries and supercapacitors. IEEE Reg. 2012, 1-5. [CrossRef] 
21. Jarushi, A.; Schofield, N. Modelling and Analysis of Energy Source Combinations for Electric Vehicles. World 2009, 3, 1-7. [CrossRef]

22. Omar, N.; Van Mierlo, J.; Van Mulders, F.; Van den Bossche, P. Assessment of Behaviour of Super Capacitor-battery System in Heavy Hybrid Lift Truck Vehicles. J. Asian Electr. Veh. 2009, 7, 1277-1282. [CrossRef]

23. Lencwe, M.J. Performance Studies of Lead Acid Batteries for Transport Vehicles. In Proceedings of the 2017 IEEE PES PowerAfrica, Accra, Ghana, 27-30 June 2017; pp. 528-532.

24. Ceraolo, M.; Lutzemberger, G.; Poli, D. State-Of-Charge Evaluation Of Supercapacitors. J. Energy Storage 2017, 11, 211-218. [CrossRef]

25. Daowd, M.; Omar, N.; van den Bossche, P.; van Mierlo, J. A review of passive and active battery balancing based on MATLAB/Simulink. Int. Rev. Electr. Eng. 2011, 6, 2974-2989. [CrossRef]

26. Tibude, V.; Tarnekar, S.G. Co-Working of Solar Panel-Battery-Super capacitor for Electric Vehicle. Int. J. Eng. Res. Electr. Electron. Eng. 2016, 2, 7-13.

27. Seim, L.H. Modeling, Control and Experimental Testing of a Supercapacitor/Battery Hybrid System-Passive and Semi-Active Topologies. Master's Thesis, Norwegian University of Life Sciences, Ås, Norway, 2011.

28. Wieczorek, M.; Lewandowski, M. Hybrid Energy Storage System For Electric Vehicles Hybrydowy Zasobnik Do Zastosowania. Czas. Tech. Elektrotech. 2016, 152-161. [CrossRef]

29. D'Arco, S.; Iannuzzi, D.; Pagano, E.; Tricoli, P. Energy management of electric road vehicles equipped with supercaps. VDI Ber. 2004, 1852, 507-519.

30. Passalacqua, M.; Lanzarotto, D.; Repetto, M.; Marchesoni, M. Advantages of Using Supercapacitors and Silicon Carbide on Hybrid Vehicle Series Architecture. Energies 2017, 10, 920. [CrossRef]

31. Lahyani, A.; Sari, A.; Lahbib, I.; Venet, P. Optimal hybridization and amortized cost study of battery/supercapacitors system under pulsed loads. J. Energy Storage 2016, 6, 222-231. [CrossRef]

(C) 2018 by the authors. Licensee MDPI, Basel, Switzerland. This article is an open access article distributed under the terms and conditions of the Creative Commons Attribution (CC BY) license (http:/ / creativecommons.org/licenses/by/4.0/). 